\title{
A OPOSIÇÃO FAVELA-BAIRRO NO ESPAÇO SOCIAL DO RIO DE JANEIRO
}

\author{
Luiz Cesar de Queiroz Ribeiro \\ Professor do IPPUR da Universidade Federal do Rio de Janeiro \\ LuCiana Corrêa do Lago \\ Professora do IPPUR da Universidade Federal do Rio de Janeiro
}

\begin{abstract}
Resumo: O trabalho tem como objetivo traçar o perfil social da população residente em favelas na metrópole do Rio de Janeiro a partir de dois enfoques analíticos: a heterogeneidade social no interior do universo estudado e a distância social entre tal população e aquela em seu entorno. Essa perspectiva nos permitirá refletir sobre a imagem da favela como o locus principal da pobreza excludente. Para tanto, serão analisados indicadores de ocupação, renda, instrução, padrão familiar, migração, cor e idade, construídos com os dados do Censo Demográfico 1991 e da Contagem da População 1996.

Palavras-chave: favela; segregação urbana; desigualdades sociais.
\end{abstract}

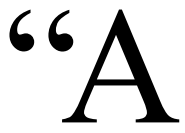
s 'favelas' - criação genuinamente carioca, não observada em nenhuma outra cidade, mesmo no Brasil - não constituem puramente impiedoso crime contra a estética, elas são particularmente uma grave e permanente ameaça à tranqüilidade e à salubridade públicas.

Erigidas contra todos os preceitos da higiene: sem água, sem esgotos, sem a mínima parcela de limpeza, sem remoção de lixo; são como largas sentinas cobertas de dejetos e dos demais resíduos da existência humana, amontoados de imundícies e podridões repastando nuvens de moscas, infiltrando nos quarteirões da cidade toda a sorte de moléstia e de impurezas.

Desprovidas de qualquer espécie de policiamento, construídas livremente de latas e frangalhos em terrenos do Patrimônio Nacional, libertadas de todos os impostos, alheias a toda ação fiscal: são excelente estímulo à indolência, atraente chamariz de vagabundos, reduto de capoeiras, vallacoitos de larápios que levam a insegurança e a intranqüilidade aos quatro cantos da cidade pela multiplicação dos assaltos e dos furtos" (Pimenta, 1926). ${ }^{1}$

"A única solução que existe para se recuperar um território que está em poder do inimigo é iniciar uma ação bélica. Trata-se de pôr em prática uma tática de guerra, com a ocupação, ostensiva e poderosa, de todo o território a ser conquistado.
Ocupada militarmente a área reconquistada, os moradores devem ser ajudados a sair dali, pois o território reconquistado vai ser liberado da presença do crime. Vai ser reflorestado, se for o caso. Ou vai servir para uma escola, para um posto de saúde ou para uma delegacia. Enfim, vai ter uma destinação pública e social.

Ao reassentar os moradores em suas novas residências, o poder público deve cuidar para que eles possam ter, daí em diante, a mesma qualidade de vida de qualquer cidadão carioca, livre de quadrilhas e de chefes de gangues" (Cavalcanti, 1996).

Essas duas citações ilustram a longevidade do chamado "problema da favela" no Rio de Janeiro. Expressam também, de maneira condensada, a trajetória da principal (di)visão da sociedade carioca, centrada na separação entre a favela e a cidade. Desde o início do século XX, com efeito, as favelas vêm sendo representadas como pertencentes a um outro mundo social e cultural, como se fossem "uma cidade à parte", já escrevia Olavo Bilac. A proximidade espacial com os bairros de classe média alta, urbanisticamente organizados e providos de equipamento e serviços urbanos, produziu um forte contraste social que serve de evidência auto-demonstrada da existência das duas cidades.

Durante a década de 70, no cerne da crítica à chamada "teoria da marginalidade urbana", buscou-se demonstrar o equívoco dos discursos dualistas sobre as favelas, man- 
tidos por instituições, governos e parte da academia. Como? Demonstrando a existência de semelhanças entre as favelas e os espaços populares, em termos de estrutura e práticas sociais. Constatando que nas favelas não havia só migrantes do campo e tampouco nelas observava-se a sobrevivência da cultura folk, as favelas passam a ser vistas como "complexo coesivo, extremamente forte em todos os níveis: família, associação voluntária e vizinhança" (Boschi, 1970). Outros demonstraram que a vida nas favelas era marcada "pela amizade e espírito cooperativo e relativamente livre de crime e da violência" (Perlman, 1977:136). Encontrou-se na favela uma estrutura social diversificada, chegando-se mesmo a observar a existência de setores identificados como a "burguesia favelada" e que nela se fazia política como nos outros espaços populares (Silva, 1967). Também identificou-se a existência de relações de sociabilidade entre "mundo da favela" e "mundo dos bairros", inicialmente pela inserção dos moradores da favela no mercado de trabalho.

Nos dias de hoje, as representações dualistas das favelas retornam ao debate público sobre a sociedade urbana carioca. Em primeiro lugar, pelos efeitos, no campo acadêmico, da absorção de conceitos e noções teóricas com os quais se estrutura hoje o debate internacional sobre os impactos sociais e espaciais das mudanças econômicas nas cidades. Tornou-se expressão de prestígio intelectual o uso de termos tais como "gueto", "exclusão social" e "nova marginalidade" nas análises sobre o "problema da favela". Assume-se como axioma que as mudanças em curso no mundo do trabalho estariam desfazendo as relações de integração da favela com a cidade. A inclusão do narcotráfico e da violência urbana na agenda da academia reforça a legitimidade da concepção dualista, uma vez que a vida organizativa da favela estaria sendo substituída por um estado de anomia. Não raro, encontramos menções que associam as favelas cariocas aos guetos negros americanos.

A utilização freqüente pela mídia de metáforas tais como "cidade partida", "desordem urbana", entre outras, por outro lado, vem dotando a concepção dualista da favela de legitimidade social. Em contrapartida emergem demandas, por parte de governos e instituições ligadas à gestão pública da pobreza, de novos discursos sobre a favela que subsidiem a política de integração da favela ao bairro.

Em resumo, assistimos hoje à produção intensa de imagens, idéias e práticas que re-editam o antigo mito da favela como um outro mundo social à parte da cidade, diferente, identificado pela carência e desorganização.
A proposta deste trabalho é submeter essa (di)visão da cidade do Rio de Janeiro a uma reflexão crítica, a partir da avaliação empírica das diferenças demográficas e sociais entre o mundo da favela e o da cidade. O texto está dividido da seguinte maneira: na primeira parte, examina-se a evolução da população moradora em favelas no período de 1940 a 1996. Na segunda, são analisados os principais traços sociodemográficos da população residente nas favelas e nos bairros da cidade. Por fim, avalia-se a distância social entre moradores em favela e em bairros segundo a renda.

\section{QUESTÕES CONCEITUAIS E METODOLÓGICAS}

Os conceitos de espaço e de distância sociais são utilizados classicamente na sociologia para desvendar os mecanismos que regulam os processos de interação humana nas formas societárias de vida coletiva. Eles estão presentes nas obras de autores como Simmel (1971), Sorokin (1973), Park (1924), entre outros. Podemos, no entanto, identificar duas concepções distintas desses conceitos: uma psicossocial, que entende a distância social como o resultado de atitudes de simpatia e antipatia de certos grupos em relação a outros (Bogardus, 1959), e outra propriamente sociológica (Sorokin, 1973; Bourdieu, 1979), na qual a distância social entre os indivíduos resulta das relações das posições sociais nas quais estão inseridos. Nessa segunda corrente, a subjetividade dos indivíduos tem importância, mas como resultado da sua inserção no mundo social, já que as "similitudes na posição social dos indivíduos ocasionam, geralmente, modos de pensar semelhantes, uma vez que implica hábitos, interesses, costumes, valores e tradições, inculcados nas pessoas por grupos sociais semelhantes, aos quais estas pessoas pertencem" (Sorokin, 1973:227).

É na sociologia de Bourdieu (1979; 1993), contudo, que o conceito de distância social ganha importância analítica. Em sua visão espacial da sociedade, Bourdieu compreende o espaço social como formado por relações de proximidade e separação que são, antes de mais nada, relações hierárquicas. Por outro lado, os lugares no espaço social são definidos pelas posições geradas pela distribuição desigual do volume e da composição do capital (econômico, social e simbólico), as quais expressam as relações de dominação na sociedade entre as classes sociais.

"A idéia de diferença, de separação, está no fundamento da própria noção de espaço, conjunto de posições dis- 
tintas e coexistentes, exteriores umas às outras, definidas umas em relação às outras por sua exterioridade mútua e por relações de proximidade, de vizinhança ou de distanciamento e, também, por relações de ordem, como acima, abaixo e entre. Várias características dos membros da pequena burguesia, por exemplo, podem ser deduzidas do fato de que eles ocupam uma posição intermediária entre duas posições extremas, sem serem objetivamente identificáveis e subjetivamente identificados com uma ou com outra" (Bourdieu, 1993:18).

Compreendendo a cidade como a "objetivação" do espaço social, a análise das proximidades e distâncias sociais entre favela e o restante da cidade implica avaliar a sua posição na (di)visão do mundo social carioca. Essa análise, porém, não é trivial, pois pressupõe superar duas tendências presentes nas formas hegemônicas de representação da distinção social, que muitas vezes surgem como realidades auto-evidenciadas, portanto inquestionáveis pelo discurso científico. Trata-se das tendências à naturalização e à substancialização da ordem social, nas quais têm enorme importância as metáforas espaciais. Com efeito, elas nos produzem a ilusão de que as propriedades sociais de uma prática ou os atributos de um grupo podem ser explicados por eles mesmos, sem levar em consideração que o real na sociedade é sempre relacional e, como tal, construído socialmente.

"A estrutura do espaço social se manifesta, em contextos mais diversos, sob a forma de oposições espaciais, o espaço habitado (ou apropriado) funcionando como uma espécie de simbolização espontânea do espaço social. Não há espaço em uma sociedade hierarquizada que não seja hierarquizado e que não exprima as hierarquias e as distâncias sociais, sob uma forma (mais ou menos) deformada e sobretudo mascarada pelo efeito de naturalização que implica a inscrição durável das realidades sociais no mundo natural: as diferenças produzidas pela lógica histórica podem assim parecer surgidas da natureza das coisas (é suficiente pensar na idéia de 'fronteira natural' " (Bourdieu, 1993:160).

A avaliação crítica da separação entre favela e cidade deve, portanto, começar pela crítica do senso comum que sustenta essa distinção social, para posteriormente reconstruí-la cientificamente como objeto de conhecimento. Seguindo as pistas do caminho analítico proposto por Wacquant (2000) para analisar o lugar dos guetos no espaço social da sociedade americana, a nossa tarefa comportaria as seguintes atividades:
- identificar as categorias do senso comum com as quais se produzem discursos mais ou menos eruditos sobre as favelas e seus congêneres (mocambos, baixada, etc.);

- reconstruir a história dessas categorias, procurando identificar quais as suas funções no sistema de classificação da sociedade brasileira, ou seja, nas formas hegemônicas pelas quais as divisões e desigualdades sociais são representadas, que podem ser de isolamento, separação e reserva de força de trabalho;

- analisar a hierarquia do espaço social, fazendo a necessária distinção analítica entre a condição social da favela, isto é, as suas características sociodemográficas, urbanísticas e ambientais, e sua posição no espaço social da cidade, o que implica pensar a favela como um lugar na hierarquia socioespacial do Rio de Janeiro. A maioria das análises restringe-se a avaliar a condição social da favela, buscando-se descrever as características e os atributos que explicariam a posição de isolamento ou separação e inferioridade;

- analisar a demanda de discurso público sobre a marginalidade. Há uma investida intelectual na formulação do discurso sobre a marginalidade e a exclusão que não está desconectada das necessidades da gestão social da pobreza por meio da intervenção pública. Muitas vezes, o surgimento de problemas na manutenção da ordem social e simbólica da cidade gera novas demandas - por parte das instituições encarregadas pela gestão social da pobreza de discursos públicos sobre os pobres, suas formas de vida e de moradia.

Esta análise não pretende percorrer todas essas etapas. A proposta deste texto é apenas identificar a situação social das favelas a partir da avaliação empírica das diferenças sociodemográficas que as distanciam e aproximam da cidade. Para tanto, serão utilizadas fontes de informações diferentes, compreendendo períodos distintos - Censo Demográfico 1991 e Contagem da População 1996. Ao final do texto encontra-se o esboço de uma reflexão sobre a pertinência da separação da favela e da cidade na compreensão dos princípios de construção e reprodução do espaço social da cidade do Rio de Janeiro.

\section{EVOLUÇÃO DA POPULAÇÃO RESIDENTE EM FAVELA}

Os dados censitários de 1950 a 1991 mostram que a taxa de crescimento anual da população favelada do Rio de Janeiro começou a decrescer na década de 60 , sofren- 
do uma queda brusca nos anos 70 . Tal queda se deve a três fatores (Tabela 1). Em primeiro lugar, a diminuição do ritmo de crescimento populacional não foi relativa apenas aos residentes em favelas, mas a toda a população carioca. No período 1950-1960 a população cresceu cerca de $3 \%$ ao ano, e os favelados, $7 \%$ ao ano. Na década de 70 esses percentuais caíram para $1,8 \%$ e $2,5 \%$, respectivamente. Nesse período o movimento migratório em direção à metrópole do Rio de Janeiro começava a perder o ímpeto verificado nos anos 40 e 50, e a capital, principal área de atração desses fluxos, sofreu os impactos dessa mudança. Nota-se, entretanto, que a proporção de favelados em relação ao total da população continuou aumentando, até mesmo no período 1970-1980, quando a taxa de crescimento dos primeiros alcançou seu menor valor (Tabela 1). Em outras palavras, o ritmo de crescimento da população favelada se manteve bem acima da progressão dos demais moradores.

O segundo fator relacionado à queda da taxa de crescimento da população favelada entre as décadas de 60 e 70 foi a "abertura" da periferia metropolitana aos trabalhadores pobres por meio da produção extensiva de lotes urbanos, iniciada na década de 50 e expandida até os anos 70. Nesse período, o loteamento periférico, com baixos investimentos em infra-estrutura e comercialização a longo prazo, tornou-se o principal meio de acesso dos pobres à casa própria. Com efeito, houve um redirecionamento dos fluxos migratórios inter e intra-regionais para essas "novas" áreas, especialmente os oriundos do próprio município do Rio de Janeiro, o que gerou a diminuição do número de migrantes na capital.

Por último, cabe mencionar os impactos da política de remoção de favelas nas décadas de 60 e 70 . Segundo Santos, 175.800 pessoas haviam sido removidas até 1968 , mas foi a partir desse ano, até 1973, que o programa foi mais

\section{TABELA 1}

Crescimento da População Total e Favelada Município do Rio de Janeiro - 1950/1991

\begin{tabular}{|c|c|c|c|c|c|}
\hline \multirow[t]{2}{*}{ Anos } & \multirow{2}{*}{$\begin{array}{l}\text { População } \\
\text { do Município } \\
\text { (A) }\end{array}$} & \multirow{2}{*}{$\begin{array}{l}\text { População } \\
\text { Favelada } \\
\text { (B) }\end{array}$} & \multicolumn{2}{|c|}{$\begin{array}{c}\text { Crescimento Populacional } \\
\text { a.a. }(\%)\end{array}$} & \multirow[t]{2}{*}{$\begin{array}{l}B / A \\
(\%)\end{array}$} \\
\hline & & & do Município & da Favela & \\
\hline 1950 & 2.375 .280 & 169.305 & - & - & 7,13 \\
\hline 1960 & 3.300 .431 & 335.063 & 3,34 & 7,06 & 10,15 \\
\hline 1970 & 4.251 .918 & 565.135 & 2,57 & 5,37 & 13,29 \\
\hline 1980 & 5.090 .723 & 722.424 & 1,82 & 2,49 & 14,19 \\
\hline 1991 & 5.480 .768 & 962.793 & 0,67 & 2,65 & 17,57 \\
\hline
\end{tabular}

Fonte: Fundação IBGE. Censos Demográficos; Iplanrio, 1991. sistemático e intenso. Vale mencionar o caráter seletivo de tal política, na medida em que $70 \%$ dos domicílios removidos localizavam-se na zona sul, na Tijuca e no Méier. O resultado foi a perda de representatividade das favelas da zona sul: se, em 1950, 25,4\% da população favelada estava na zona sul, em 1970 apenas 9,6\% dela ainda residia na área (Castro, 1979).

Esse conjunto de fatores alimentou a idéia, difundida no final dos anos 70, de que as favelas tenderiam a desaparecer do cenário urbano carioca. Entretanto, houve uma retomada do crescimento das favelas na década de 80 , tanto pela densificação das antigas quanto pelo surgimento de novas.

Por que voltaram a crescer as favelas na cidade do Rio de Janeiro, exatamente no momento em que ocorreu uma forte queda do crescimento demográfico da cidade? Em primeiro lugar, em razão da mudança da dinâmica do crescimento metropolitano do Rio de Janeiro. Com efeito, o crescimento extensivo-periférico, que gerou oportunidades de acesso à casa própria para amplos segmentos sociais, entrou em colapso, entre outras razões, pelo encarecimento da terra e pela perda da capacidade de endividamento dos trabalhadores em geral, atingindo aqueles com menor qualificação e sem proteção das leis trabalhistas. Somemse ainda as transformações na conjuntura política fluminense a partir de 1982, data que marca o início da adoção pelos poderes públicos locais (governo estadual e municipal) de políticas de reconhecimento das favelas e dos loteamentos irregulares e clandestinos como solução dos problemas de moradia das camadas populares. Essas políticas, ao proporem a legalização da posse da terra e a urbanização das favelas, reduziram as incertezas quanto à manutenção dos moradores em suas ocupações e criaram expectativas de melhores condições de vida, cujo resultado foi a redução das barreiras para novas ocupações.

Nos anos 90 o ritmo de crescimento da população favelada (1,6\% ao ano) manteve-se bem acima do referente ao da população não-favelada $(0,0 \%$ ao ano). O resultado foi o aumento da proporção dos que residem em favelas em relação ao total da população carioca, que passou, em cinco anos, de $16 \%$ para $17 \%$. No entanto, essas tendências variaram significativamente entre as diferentes regiões da cidade. As duas zonas de expansão do município - o eixo elitizado da Barra/Jacarepaguá e o eixo popular da zona oeste - apresentaram as maiores taxas de crescimento tanto da população favelada $(3,9 \%$ e $3,4 \%$ ao ano respectivamente) quanto da não-favelada $(1,6 \%$ e $1,3 \%$ ao ano). Nas três zonas consolidadas, todas com crescimen- 
TABELA 2

População Residente em Favela e Fora da Favela

Município do Rio de Janeiro - 1991/1996

\begin{tabular}{|c|c|c|c|c|c|c|}
\hline \multirow{2}{*}{ Grandes Zonas } & \multicolumn{2}{|c|}{ Crescimento Absoluto } & \multicolumn{2}{|c|}{ Crescimento Anual (\%) } & \multirow{2}{*}{$\begin{array}{c}\text { População Favelada/ } \\
\text { População Total } \\
1991(\%)\end{array}$} & \multirow{2}{*}{$\begin{array}{c}\text { População Favelada/ } \\
\text { População Total } \\
1996(\%)\end{array}$} \\
\hline & Favela & Não-Favela & Favela & Não-Favela & & \\
\hline Total do Município & 71.089 & 842 & 1,6 & 0,0 & 16,1 & 17,2 \\
\hline Centro/Zona Sul & 16.110 & -27.035 & 2,4 & 0,8 & 14,9 & 17,0 \\
\hline Barra/Jacarepaguá & 13.523 & 29.364 & 3,9 & 1,6 & 15,0 & 16,6 \\
\hline Zona Norte & -2.636 & -23.123 & $-1,1$ & $-1,4$ & 12,6 & 12,7 \\
\hline Subúrbio & 21.367 & -57.672 & 0,8 & $-0,6$ & 20,6 & 21,8 \\
\hline Zona Oeste & 22.725 & 79.308 & 3,4 & 1,3 & 9,6 & 10,5 \\
\hline
\end{tabular}

Fonte: Fundação IBGE. Censo Demográfico 1991 e Contagem da População 1996.

to negativo da população não-favelada, destaca-se a zona sul, com uma taxa de crescimento dos residentes em favelas de 2,4\% ao ano, aumentando de 14,9\% em 1991 para $17 \%$ em 1996 a proporção desses residentes em relação à população total da região. A zona norte da cidade foi a única região que apresentou perda absoluta de população residente em favela.

Como crescem as favelas? Classicamente, atribuiu-se à migração, particularmente à do Nordeste, a causa do crescimento demográfico nas favelas. Os dados censitários, no entanto, indicam que a migração explica cada vez menos o acelerado processo de favelização em curso na cidade. $\mathrm{Na}$ zona oeste, por exemplo, região que apresentou, entre 1991 e 1996, o maior incremento absoluto de população favelada (em torno de 22 mil pessoas), apenas 2 mil e 600 pessoas residentes em favelas eram migrantes ${ }^{2}$ da década de 90. Podemos inferir que o surgimento e a expansão de novas favelas (localizadas predominantemente na zona oeste) têm ocorrido por meio da mobilidade espacial no interior do próprio município, seja do bairro para a favela, seja de favelas consolidadas para favelas recentes. A fuga do aluguel, tanto no mercado formal quanto informal, e a redução da oferta de habitação ou lote popular explicam essa mobilidade em direção às favelas periféricas. Vale lembrar que o valor do aluguel de um imóvel nas favelas das zonas sul e norte pode equivaler, hoje, ao de um apartamento em Copacabana ou no Centro.

A mobilidade intramunicipal tem menor peso explicativo quando se observa o incremento populacional nas favelas já consolidadas das zonas sul e suburbana. Na zona sul da cidade cerca de $40 \%$ do incremento da população favelada, nos primeiros cinco anos da década de 90 , era composto por migrantes de fora do município, em sua maior parte do
TABELA 3

Perfil Socioocupacional da População Ocupada e do Migrante Nordestino Ocupado, Residentes nas Favelas da Zona Sul e da Zona Norte Município do Rio de Janeiro - 1991

Em porcentagem

\begin{tabular}{lcc}
\hline Categorias & \multicolumn{2}{c}{ População Ocupada } \\
\cline { 2 - 3 } Socioocupacionais (1) & População Residente & Migrante Nordestino \\
\hline Elite & 1,3 & 0,4 \\
Pequena Burguesia & 3,4 & 0,7 \\
Classe Média & 17,0 & 6,4 \\
Operário & 20,9 & 15,7 \\
Proletário do Terciário & 37,3 & 59,7 \\
Subproletário & 19,8 & 16,9
\end{tabular}

Fonte: Fundação IBGE. Censo Demográfico 1991.

(1) Elite: empresários e executivos dos setores público e privado e profissionais de nível superior; Pequena Burguesia: pequenos empregadores do serviço e comércio; Classe Média: empregados em ocupações de rotina, supervisão, segurança, ensino básico e técnicos: Operário: trabalhadores da indústria e da construção civil; Proletário do Terciário: prestadores de serviço e comerciários; Subproletário: trabalhadores domésticos, ambulantes e biscateiros.

Nordeste. Nesse sentido, a possível "expulsão branca", gerada pela valorização imobiliária, de residentes mais pauperizados das favelas centrais deve ser relativizada diante da possibilidade de "entrada" nesses espaços de uma população migrante cujo perfil social era, em média, inferior ao dos já residentes. Na Tabela 3, observa-se o perfil socioocupacional mais elevado do conjunto da população ocupada residente nas favelas das zonas sul e norte, em comparação com o perfil dos migrantes nordestinos que se dirigiram para essas áreas na década de 80 . As redes familiares funcionam, para o migrante recém-chegado, como importante mecanismo de acesso à moradia $\mathrm{e}$ de inserção na economia urbana. Por sua vez, a localização dessas favelas em áreas com grande demanda por trabalho de baixa qualificação nos setores de serviços e cons- 


\begin{tabular}{|c|c|c|c|c|c|c|c|}
\hline \multicolumn{8}{|c|}{$\underline{\text { TABELA } 4}$} \\
\hline \multicolumn{8}{|c|}{$\begin{array}{l}\text { População, por Faixa Etária, segundo a Localização do Domicílio na Favela ou Fora da Favela } \\
\qquad \text { Município do Rio de Janeiro - } 1996\end{array}$} \\
\hline \multirow{2}{*}{ Localização do Domicílio } & \multicolumn{7}{|c|}{ Faixa Etária } \\
\hline & Total & $0-10$ Anos & 11-14 Anos & 15-24 Anos & $25-44$ Anos & 45-64 Anos & 65 Anos e Mais \\
\hline \multicolumn{8}{|l|}{ Total } \\
\hline Favela & 100,0 & 22,8 & 8,0 & 19,7 & 32,1 & 13,3 & 4,1 \\
\hline Fora da Favela & 100,0 & 15,1 & 6,4 & 16,6 & 31,9 & 20,3 & 9,6 \\
\hline \multicolumn{8}{|l|}{ Centro/Zona Sul } \\
\hline Favela & 100,0 & 21,0 & 7,1 & 19,6 & 34,0 & 13,8 & 4,5 \\
\hline Fora da Favela & 100,0 & 9,8 & 4,5 & 14,5 & 31,5 & 24,1 & 15,6 \\
\hline \multicolumn{8}{|l|}{ Barra/Jacarepaguá } \\
\hline Favela & 100,0 & 23,3 & 7,6 & 20,7 & 34,6 & 11,3 & 2,6 \\
\hline Fora da Favela & 100,0 & 15,7 & 6,7 & 17,5 & 33,8 & 19,6 & 6,7 \\
\hline \multicolumn{8}{|l|}{ Zona Norte } \\
\hline Favela & 100,0 & 22,6 & 8,3 & 19,5 & 30,8 & 13,5 & 5,2 \\
\hline Fora da Favela & 100,0 & 11,0 & 5,4 & 14,6 & 30,4 & 23,5 & 15,2 \\
\hline \multicolumn{8}{|l|}{ Subúrbio } \\
\hline Favela & 100,0 & 23,0 & 8,1 & 19,6 & 31,6 & 13,4 & 4,2 \\
\hline Fora da Favela & 100,0 & 15,0 & 6,5 & 16,4 & 31,9 & 20,8 & 9,5 \\
\hline \multicolumn{8}{|l|}{ Zona Oeste } \\
\hline Favela & 100,0 & 23,7 & 8,7 & 19,5 & 31,1 & 13,1 & 3,9 \\
\hline Fora da Favela & 100,0 & 19,1 & 7,6 & 18,4 & 32,0 & 16,9 & 6,0 \\
\hline
\end{tabular}

Fonte: Fundação IBGE. Contagem da População 1996.

trução civil se mantém como fator central para essa inserção do migrante.

\section{A DIVISÃO FAVELA-BAIRRO NO ESPAÇO DESIGUAL DA CIDADE}

A população residente nas favelas do Rio de Janeiro é significativamente mais jovem do que a que mora nos bairros da cidade, confirmando um perfil etário que é, de uma maneira geral, típico das áreas populares. Nesse sentido, é na zona oeste do município, área periférica popular, que se encontra a menor diferença entre o perfil etário da favela $\mathrm{e}$ do bairro: enquanto na favela cerca de $51 \%$ dos moradores têm até 24 anos, no bairro esse percentual é de $45 \%$ (Tabela 4). Quanto mais nos aproximamos do centro, maior a diferença de perfil e mais idosa é a população.

$\mathrm{O}$ perfil etário dos residentes em favelas não apresenta grandes variações entre as cinco zonas da cidade. $O$ percentual da população na faixa de 0 a 24 anos varia de $47,6 \%$, nas favelas da zona sul, a 51,9\%, nas da zona oeste. Vale observar, ainda, o peso relativamente menor da faixa acima de 45 anos nas favelas da Barra e de Jacarepaguá: enquanto nessa zona o percentual é de $13,9 \%$, nas demais variou entre $17 \%$ e $18,7 \%$. Esse perfil mais jovem das favelas da Barra e de
Jacarepaguá acompanha o perfil dos próprios bairros em que estão localizadas, que também apresentam menor peso relativo da faixa acima de 45 anos e maior proporção das faixas entre 15 e 24 anos e entre 25 e 44 anos. Como área de expansão para os segmentos sociais médios, essa zona atrai uma população em começo de carreira e na primeira fase do ciclo familiar (casal sem filhos ou casal com filhos pequenos). Como área de maior concentração da produção imobiliária, atrai trabalhadores para a construção civil, cujo perfil etário é relativamente jovem e cuja alternativa de uma moradia próxima se restringe às favelas da região.

Em relação à diferenciação por sexo, cabe apenas destacar uma proporção de mulheres relativamente maior nos bairros em comparação com as favelas, particularmente no centro/zona sul e Barra/Jacarepaguá.

O indicador de cor evidencia maior predominância de uma população branca nos bairros da cidade - em torno de $64 \%$ - e de uma população não-branca nas favelas em torno de $62 \%$ (Tabela 5). Esses percentuais sofrem significativa variação segundo as diferentes áreas. Enquanto no centro/zona sul e Barra/Jacarepaguá mais de $80 \%$ dos moradores são brancos, na zona norte esse percentual é de apenas $48 \%$. Entre os residentes nas favelas, a variação segundo a localização geográfica é menor: as favelas 
do centro/zona sul são as que apresentam a menor proporção de não-brancos (cerca de 55\%); nas demais esse percentual varia de $62 \%$ a $65 \%$.

Os dados sobre a escolaridade da população acima de 23 anos do Rio de Janeiro (Tabela 6) evidenciam uma profunda diferença de perfil entre os residentes nas favelas e nos bairros, seja nas áreas centrais ou na periferia da cidade, embora a diferença se apresente relativamente menor na periferia. A primeira constatação é a elevada proporção, nas favelas, da população com até 7 anos de estudo: acima de $70 \%$ em todas as zonas! Entre os moradores dos bairros, o menor percentual dessa faixa foi de $19 \%$ na zona norte, e o mais elevado foi de $52 \%$, na zona oeste. Em outras palavras, o nível de instrução nas favelas é ainda inferior ao observado nos bairros populares da periferia da cidade.

Uma segunda evidência refere-se à pequena diferenciação, entre as cinco zonas, dos perfis de escolaridade dos moradores em favelas. As diferenças mais significativas são os percentuais relativamente maiores (i) daqueles com até 3 anos de estudo nas favelas da Barra/Jacarepaguá $(36,6 \%)$ e da zona norte $(35,6 \%)$ e (ii) daqueles com nível superior nas favelas do centro/zona sul $(1,3 \%)$. É interessante destacar o fato de que os residentes das favelas

\section{TABELA 5}

População, por Sexo e Cor, segundo a Localização do Domicílio na Favela ou Fora da Favela Município do Rio de Janeiro - 1996

Em porcentagem

\begin{tabular}{|c|c|c|c|c|}
\hline \multirow{3}{*}{$\begin{array}{l}\text { Localização } \\
\text { do Domicílio }\end{array}$} & \multicolumn{4}{|c|}{ Em porcentagem } \\
\hline & \multicolumn{2}{|c|}{ Sexo } & \multicolumn{2}{|c|}{ Cor } \\
\hline & Homem & Mulher & Branca & Não-Branca \\
\hline \multicolumn{5}{|l|}{ Total } \\
\hline Favela & 48,8 & 51,2 & 38,0 & 62,0 \\
\hline Não-Favela & 46,6 & 53,4 & 64,3 & 35,7 \\
\hline \multicolumn{5}{|c|}{ Centro/Zona Sul } \\
\hline Favela & 48,4 & 51,6 & 44,4 & 55,6 \\
\hline Não-Favela & 43,7 & 56,3 & 84,0 & 16,0 \\
\hline \multicolumn{5}{|c|}{ Barra/Jacarepaguá } \\
\hline Favela & 48,2 & 51,8 & 34,6 & 65,4 \\
\hline Não-Favela & 44,2 & 55,8 & 87,1 & 12,9 \\
\hline \multicolumn{5}{|l|}{ Zona Norte } \\
\hline Favela & 49,3 & 50,7 & 37,4 & 62,6 \\
\hline Não-Favela & 48,4 & 51,6 & 47,9 & 52,1 \\
\hline \multicolumn{5}{|l|}{ Subúrbio } \\
\hline Favela & 49,4 & 50,6 & 36,4 & 63,6 \\
\hline Não-Favela & 47,4 & 52,6 & 65,8 & 34,2 \\
\hline \multicolumn{5}{|l|}{ Zona Oeste } \\
\hline Favela & 48,7 & 51,3 & 37,3 & 62,7 \\
\hline Não-Favela & 46,7 & 53.3 & 62.9 & 37,1 \\
\hline
\end{tabular}

Fonte: Fundação IBGE. Censo Demográfico de 1991. mais recentes, localizadas na periferia, não apresentam um perfil de instrução inferior àqueles das favelas centrais consolidadas. A menor proporção dos migrantes - especialmente dos que provêm de longa distância - nas favelas periféricas pode explicar em parte essa equivalência no nível de escolaridade.

Analisando o perfil socioocupacional da população ocupada nas favelas e nos bairros observa-se, assim como no perfil de instrução, uma profunda diferença entre os dois universos de análise (Tabela 7). No entanto, essas diferenças variam significativamente entre as cinco zonas da cidade.

Uma primeira evidência é o corte favela-bairro no que se refere ao percentual da elite, que se mostra bastante acentuado apenas nas seguintes áreas: centro/zona sul, Barra/Jacarepaguá e zona norte. A maior diferença, nesse caso, está na zona norte, onde a elite representa $28,5 \%$ dos moradores dos bairros e $0,9 \%$ dos residentes em favelas. $\mathrm{Na}$ zona oeste, por outro lado, a elite apresenta baixíssima representatividade tanto nos bairros quanto nas favelas: $3,6 \%$ e $0,6 \%$, respectivamente. Em relação à classe média, o corte favela-bairro é menos acentuado: nas favelas do centro/zona sul, 19,2\% dos moradores es-

TABELA 6

População Acima de 23 Anos, por Anos de Estudo, segundo a Localização do Domicílio na Favela ou Fora da Favela Município do Rio de Janeiro - 1996

Em porcentagem

\begin{tabular}{|c|c|c|c|c|c|}
\hline \multirow{2}{*}{$\begin{array}{l}\text { Localização } \\
\text { do Domicílio }\end{array}$} & \multicolumn{5}{|c|}{ Anos de Estudo } \\
\hline & Até 3 & 4 a 7 & 8 a 10 & 11 a 14 & Mais de 15 \\
\hline \multicolumn{6}{|l|}{ Total } \\
\hline Favela & 33,8 & 40,4 & 16,5 & 8,6 & 0,7 \\
\hline Não-Favela & 11,8 & 25,0 & 17,1 & 27,4 & 18,7 \\
\hline \multicolumn{6}{|c|}{ Centro/ZonaSul } \\
\hline Favela & 33,7 & 40,1 & 10,9 & 8,0 & 1,3 \\
\hline Não-Favela & 7,2 & 14,4 & 11,4 & 28,0 & 38,9 \\
\hline \multicolumn{6}{|c|}{ Barra/Jacarepaguá } \\
\hline Favela & 36,6 & 38,4 & 15,4 & 9,0 & 0,7 \\
\hline Não-Favela & 12,0 & 20,3 & 13,4 & 27,1 & 27,2 \\
\hline \multicolumn{6}{|l|}{ Zona Norte } \\
\hline Favela & 35,6 & 39,9 & 16,2 & 7,6 & 0,7 \\
\hline Não-Favela & 5,3 & 13,7 & 11,1 & 30,4 & 39,5 \\
\hline \multicolumn{6}{|l|}{ Subúrbio } \\
\hline Favela & 33,8 & 40,4 & 16,6 & 8,7 & 0,6 \\
\hline Não-Favela & 11,2 & 27,0 & 19,0 & 29,8 & 13,0 \\
\hline \multicolumn{6}{|l|}{ Zona Oeste } \\
\hline Favela & 31,6 & 41,8 & 16,6 & 9,3 & 0,7 \\
\hline Não-Favela & 18,0 & 34,0 & 20,9 & 21,8 & 5,2 \\
\hline
\end{tabular}

Fonte: Fundação IBGE. Censo Demográfico de 1991. 
TABELA 7

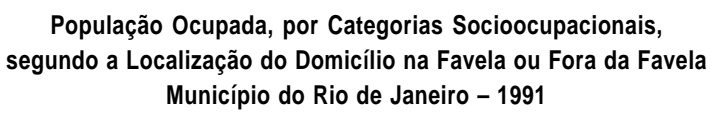
Município do Rio de Janeiro - 1991

Em porcentagem

\begin{tabular}{|c|c|c|c|c|c|c|}
\hline \multirow{2}{*}{$\begin{array}{l}\text { Localização do } \\
\text { Domicílio }\end{array}$} & \multicolumn{6}{|c|}{ Categorias Socioocupacionais (1) } \\
\hline & Elite & $\begin{array}{c}\text { Pequena } \\
\text { Burguesia }\end{array}$ & $\begin{array}{l}\text { Classe } \\
\text { Média }\end{array}$ & Operário & $\begin{array}{l}\text { Proletários do } \\
\text { Terciário }\end{array}$ & Subproletários \\
\hline \multicolumn{7}{|l|}{ Total } \\
\hline Favela & 0,8 & 5,6 & 15,2 & 27,8 & 33,5 & 17,1 \\
\hline Não-Favela & 13,0 & 8,0 & 34,5 & 12,4 & 23,1 & 9,0 \\
\hline \multicolumn{7}{|l|}{ Centro/Zona Sul } \\
\hline Favela & 1,8 & 5,5 & 19,2 & 16,0 & 40,1 & 17,4 \\
\hline Não-Favela & 26,6 & 8,3 & 32,6 & 3,2 & 18,3 & 11,0 \\
\hline \multicolumn{7}{|c|}{ Barra/Jacarepaguá } \\
\hline Favela & 0,7 & 5,1 & 10,8 & 27,0 & 36,6 & 19,8 \\
\hline Não-Favela & 16,8 & 8,5 & 29,5 & 12,1 & 22,8 & 10,4 \\
\hline \multicolumn{7}{|l|}{ Zona Norte } \\
\hline Favela & 0,9 & 4,9 & 15,7 & 21,9 & 35,5 & 21,1 \\
\hline Não-Favela & 28,5 & 9,1 & 37,3 & 3,4 & 14,3 & 7,4 \\
\hline \multicolumn{7}{|l|}{ Subúrbio } \\
\hline Favela & 0,6 & 5,5 & 15,0 & 30,6 & 31,8 & 16,4 \\
\hline Não-Favela & 8,8 & 8,2 & 39,2 & 12,9 & 23,7 & 7,1 \\
\hline \multicolumn{7}{|l|}{ Zona Oeste } \\
\hline Favela & 0,6 & 6,5 & 13,9 & 30,5 & 31,5 & 17,0 \\
\hline Não-Favela & 3,6 & 6,7 & 28,3 & 21,9 & 28,6 & 11,0 \\
\hline
\end{tabular}

Fonte: Fundação IBGE. Censo Demográfico 1991.

(1) Elite: empresários e executivos dos setores público e privado e profissionais de nivel superior; Pequena Burguesia: pequenos empregadores do serviço doméstico e comércio; Classe Média: empregados em ocupações de rotina, supervisão, segurança, ensino básico e técnicos; Operários: trabalhadores da indústria e da construção civil; Proletários do Terciário: prestadores de serviço e comerciários; Subproletários: trabalhadores domésticos, ambulantes e biscateiros.

tão em ocupações médias, enquanto nos bairros esse percentual é de 32,6\%. Mesmo nas favelas da Barra/ Jacarepaguá, onde os moradores apresentam um perfil socioocupacional relativamente mais proletário do que o encontrado nas demais zonas, o percentual da classe média alcança $10,8 \%$.

Uma segunda evidência é a participação, não muito diferenciada, dos subproletários nas favelas e nos bairros do centro/zona sul e zona oeste: cerca de $17 \%$ nas favelas de ambas as zonas e $11 \%$ nos respectivos bairros. Não deixa de ser surpreendente o fato de cerca de $11 \%$ dos residentes nos bairros mais valorizados da cidade - centro/ zona sul e Barra/Jacarepaguá - serem subproletários, categoria composta predominantemente por trabalhadores domésticos. Essa é uma evidência de que ainda existem nessas áreas mecanismos, por meio do mercado, que garantem o acesso desses trabalhadores à moradia.

Por fim, cabe destacar a significativa diferenciação, entre as favelas, dos seus perfis socioocupacionais, segundo a área em que se encontram. As favelas do subúrbio e da zona oeste apresentam um perfil mais operário - em torno de $30 \%$ dos ocupados - do que o verificado nas favelas das demais zonas, onde a predominância dos trabalhadores do terciário é relativamente maior.

\section{DISTÂNCIA FAVELA-BAIRRO}

Nesta parte do texto, avalia-se a distância social entre favela e bairro no que concerne à renda monetária. A Tabela 8 apresenta a razão entre as médias da renda total dos moradores das favelas e as dos bairros, segundo variáveis sociodemográficas reconhecidas na literatura especializada como determinantes da renda: inserção na estrutura ocupacional, escolaridade, idade, cor e sexo. As desigualdades oriundas dessas diferenças podem expressar mecanismos de segregação e/ou discriminação de certos segmentos sociais no mercado de trabalho quando usados como critério seletivo na distribuição das oportunidades ocupacionais ou diferenciador do salário. Como são reconhecidos os diferenciais de renda entre trabalhadores brancos e não-brancos no mercado de trabalho urbano brasileiro, e como nas favelas os não-brancos têm presença expressiva, parte-se 
TABELA 8

Razão entre a Renda Média dos Moradores da Favela,

do Bairro e da Cidade

Município do Rio de Janeiro - 1991

\begin{tabular}{|c|c|c|c|c|}
\hline \multirow[b]{2}{*}{ Indicadores } & \multirow{2}{*}{$\begin{array}{c}\text { Bairro (1) } \\
\text { Não-Branco/ } \\
\text { Branco }\end{array}$} & \multirow{2}{*}{$\begin{array}{c}\text { Favela } \\
\text { Não-Branco/ } \\
\text { Branco }\end{array}$} & \multicolumn{2}{|c|}{ Cidade } \\
\hline & & & $\begin{array}{c}\text { Favela/ } \\
\text { Bairro }\end{array}$ & $\begin{array}{c}\text { Não-Branco/ } \\
\text { Branco }\end{array}$ \\
\hline \multicolumn{5}{|l|}{ Ocupação } \\
\hline Subproletariado & 0,86 & 0,91 & 0,93 & 0,87 \\
\hline Operariado & 0,73 & 0,93 & 0,84 & 0,74 \\
\hline Proletariado do Terciário & 0,63 & 0,87 & 0,68 & 0,64 \\
\hline Não-Manual Nível Médio & 0,63 & 0,85 & 0,56 & 0,63 \\
\hline \multicolumn{5}{|l|}{ Anos de Estudo } \\
\hline Sem Instrução & 0,90 & 0,81 & 0,85 & 0,88 \\
\hline De 1 a 4 Anos & 0,75 & 0,92 & 0,77 & 0,74 \\
\hline De 5 a 8 Anos & 0,76 & 0,99 & 0,75 & 0,75 \\
\hline De 9 a 11 Anos & 0,72 & 0,89 & 0,61 & 0,71 \\
\hline Mais de 12 Anos & 0,67 & 0,84 & 0,44 & 0,67 \\
\hline \multicolumn{5}{|l|}{ Idade } \\
\hline Jovem & 0,77 & 0,87 & 0,78 & 0,74 \\
\hline Adulto & 0,47 & 0,82 & 0,46 & 0,47 \\
\hline Maduro & 0,44 & 0,90 & 0,37 & 0,44 \\
\hline Idoso & 0,41 & 0,87 & 0,30 & 0,40 \\
\hline \multicolumn{5}{|l|}{ Sexo } \\
\hline Homem & 0,43 & 0,77 & 0,35 & 0,42 \\
\hline Mulher & 0,45 & 0,93 & 0,66 & 0,44 \\
\hline
\end{tabular}

Fonte: Fundação IBGE. Censo Demográfico 1991

(1) Exclui os moradores das favelas.

dessa dicotomia como ponto de referência para avaliar a distância entre favela e bairro.

Observa-se a existência de homologia entre a hierarquia ocupacional e a distância social entre moradores da favela e do bairro. Nas posições mais inferiores (empregadas domésticas, ambulantes, biscateiros) há muita proximidade entre os moradores da favela e os do bairro, já que os diferenciais de renda são bem pequenos. Na medida em que subimos na hierarquia, as distâncias aumentam, chegando ao máximo entre as ocupações não-manuais de nível médio, em que os moradores em favela têm $56 \%$ da renda dos moradores no bairro. A mesma homologia é encontrada no exame dos diferenciais de renda entre brancos e nãobrancos, embora a distância entre esses dois segmentos seja menor do que a verificada entre a favela e o bairro. Já as distâncias entre os moradores de favela são significativamente menores, o que sugere a existência de forte homogeneidade social.

Constata-se situação similar na análise por nível de escolaridade, ou seja, à maior escolaridade corresponde maior distância social entre moradores de favela e moradores de bairro, o mesmo sucedendo com a distância entre brancos e não-brancos. Foi verificada, contudo, alguma nuança. A posição de desvantagem relativa dos moradores de favela $\mathrm{e}$ dos não-brancos da cidade parece ser a mesma até a faixa de escolaridade equivalente ao primário ( 8 anos). Os diferenciais aumentam mais fortemente no corte favela/bairro nas outras faixas, atingindo o patamar de $44 \%$ entre aqueles com mais de 12 anos de instrução. Em outras palavras, os moradores de favela têm maior dificuldade em transformar seu capital escolar em renda do que o conjunto dos não-brancos. Entre os trabalhadores "sem instrução", ou seja, aqueles que estão na posição mais desfavorável no mercado de trabalho - que, como foi visto representam cerca de $70 \%$ dos moradores em favela -, constata-se uma surpreendente diferença de renda: os moradores em favela recebem $85 \%$ dos que moram no bairro.

No exame dos diferenciais por idade e gênero, verificase que a distância entre favela e bairro é semelhante à existente entre branco e não-branco.

Será que as diferenças de renda resultam de mecanismos de discriminação no mercado de trabalho dos moradores das favelas? Será que teríamos então a configuração do fenômeno da guetificação dos moradores das favelas?

\section{AS FAVELAS SÃo GUETOS?}

A análise da situação das favelas perante a dos bairros sugere a existência de importante divisão no espaço social da cidade do Rio de Janeiro. A oposição favela/bairro parece ser a expressão espacial das notórias desigualdades que marcam a sociedade brasileira, já que concentra os segmentos sociais que apresentam maiores desvantagens no acesso às oportunidades: os mais jovens, os nãobrancos e os de baixa escolaridade. Entretanto, os resultados da nossa análise indicam ser a favela o lugar de moradia dos que desfrutam de maior desvantagem entre os afortunados da cidade, uma vez que os diferenciais de renda aumentam entre os grupos com maiores chances de se igualarem aos moradores do bairro. Ao mesmo tempo, os diferenciais de renda não são desprezíveis entre os mais desafortunados da cidade.

Tais constatações parecem fortalecer as concepções dualistas da favela. Gostaríamos, porém, de terminar nosso trabalho com breves comentários que, a nosso ver, são necessários para escapar do reducionismo. Com efeito, como foi dito no início, esta análise é insuficiente para identificar a posição das favelas no espaço social da cidade. É 
imprescindível passar da análise da divisão favela/bairro para a interpretação da (di)visão dessa dicotomia socioespacial, ou seja, avaliar se as diferenças observadas são representadas legitimamente na sociedade carioca como separação e/ou inferioridade.

A reflexão sobre a distância social em termos de renda oferece a possibilidade de explorar alguns caminhos. As diferenças observadas sugerem duas explicações a respeito da simbolização da divisão favela-bairro e sua inscrição nas práticas sociais que regulam a relação entre trabalho e moradia. Na primeira, a favela seria considerada variável dependente. Ela seria a conseqüência de práticas discriminatórias no mercado de trabalho contra aqueles que moram nas favelas. Ou seja, o fato de morar em favela seria um atributo negativo, do qual resultam práticas discriminatórias quanto à determinação da renda. A situação dos moradores de favela seria idêntica à das mulheres no mercado de trabalho, já fartamente descrita na literatura sociológica e econômica. A legitimidade social dessa discriminação seria obtida pela transformação do lugar desclassificado dos moradores da favela em um habitus (Bourdieu, 1979), pelo qual se produziria a naturalização da discriminação e a conseqüente disposição dos moradores das favelas em aceitar menores salários. Esse argumento aproxima a posição da favela no espaço social do Rio de Janeiro daquela dos guetos negros americanos, segundo as análises de Wilson (1987) e Wacquant (2000), nas quais a inferioridade social dos seus moradores se reproduz como um círculo perverso.

Na segunda hipótese, a favela seria uma variável independente. Há duas variantes explicativas nesse caso. $\mathrm{Na}$ primeira, a favela seria o resultado dos baixos e incertos rendimentos dos trabalhadores que exercem posições inferiores às suas possibilidades em razão da segmentação do mercado de trabalho, cuja conseqüência é a obtenção de renda inferior. A ilustração dessa variante seria a forte presença na favela de trabalhadores da construção civil, setor produtivo no qual a escolaridade tem pouca importância na determinação do rendimento dos trabalhadores, dada a natureza manufatureira do processo de trabalho e a prevalência do trabalho autônomo. Os baixos e incertos rendimentos obtidos somente permitiriam acesso ao submercado habitacional da favela como estratégia de diminuição dos custos da moradia e do transporte. Na segunda variante, a favela resultaria da acessibilidade à fonte de renda propiciada pela localização residencial de determinados segmentos de trabalhadores que exercem ocupações temporárias, incertas e dependentes do contato pessoal entre demanda
TABELA 9

Razão entre a Renda Média dos Moradores em Favelas, segundo Grandes Áreas Município do Rio de Janeiro - 1991

\begin{tabular}{lc}
\hline Grandes Áreas & Razão \\
\hline Total & 1,00 \\
Zona Sul/Centro & 1,12 \\
Barra/Jacarepaguá & 0,94 \\
Zona Norte & 1,05 \\
Zona Oeste & 0,90 \\
Subúrbio & 0,94 \\
\hline
\end{tabular}

Fonte: Fundação IBGE. Censo Demográfico 1991.

e oferta. A ilustração dessa variante seria a forte presença de prestadores de serviços pessoais nas favelas localizadas nas áreas mais centrais da cidade. Tal hipótese estaria coerente com a constatação da relação entre o gradiente da renda média dos moradores das favelas pelas grandes áreas e o mapa social da cidade, na qual nota-se que, quanto mais próximo dos centros de concentração espacial das camadas superiores, maior a renda relativa, conforme transparece na leitura da Tabela 9.

Em resumo, nas duas variantes da segunda hipótese, a separação entre favela e não-favela expressaria a segmentação do acesso aos recursos localizados desigualmente na cidade, sejam eles os relativos à moradia ou às oportunidades de trabalho e renda. Essa nos parece a mais plausível hipótese explicativa das diferenças de renda entre favela e bairro. A renda e o seu montante explicam a seleção entre moradores da favela e do bairro. Aqueles que conseguem vencer as barreiras existentes no mercado de trabalho e aumentam a sua renda ou têm acesso a ocupações mais estáveis tendem a abandonar a favela. É o que mostram estudos sobre mobilidade residencial (Lago, 2000) entre as favelas centrais da cidade do Rio de Janeiro e a periferia metropolitana.

O último comentário diz respeito à necessidade de levar em consideração as diferenças entre as favelas quanto à sua posição no espaço social da cidade. A favela pode representar tanto um momento da mobilidade ascendente de certos segmentos sociais, quanto o seu contrário, lugar do refúgio para aqueles que estão em processo de marginalização social. A entrada nas favelas localizadas na zona sul de migrantes de outros municípios do Estado do Rio de Janeiro e da região nordestina do Brasil, todos com status social e ocupacional inferior aos dos moradores, parece indicar a situação na qual o crescimento da favela 
pode estar associado à dinâmica de mobilidade social ascendente. Em contraposição, o crescimento das favelas na zona oeste poderia expressar um movimento de mobilidade social descendente, especialmente no caso dos moradores das favelas da zona sul que, por algum motivo, se vêem obrigados a abrir mão do maior acesso à fonte de renda e ocupação. Será que essas favelas estariam transitando para uma situação de gueto, na medida em que o seu crescimento parece estar associado a um processo de isolamento social?

Não é possível responder a essa questão neste texto. Gostaríamos tão-somente de lembrar que o trabalho não é a única dimensão explicativa da exclusão social produzida pela guetificação dos negros pobres americanos, segundo as análises de Wacquant e Wilson. O gueto é também produzido pela estigmatização dos territórios onde se concentram os segmentos fragilizados economicamente, pela diminuição da densidade organizacional desses territórios e pela baixa presença do Estado. Sobretudo, a guetificação se realiza quando ocorre a desapropriação simbólica dos moradores desses territórios, na capacidade de controlar sua representação social, nas formas coletivas de classificação das divisões da sociedade e, portanto, na sua identidade como grupo. É essa despossessão que permite transformar os desiguais em proscritos sociais, e como tais vivendo na desordem ou em uma outra ordem social considerada legitimamente inaceitável.

Esse ponto nos devolve ao início deste trabalho, à reflexão sobre a importância das concepções teóricas, das imagens e das práticas presentes no atual debate público sobre a cidade partida. Que efeitos simbólicos negativos estariam sendo produzidos pelas associações cada vez mais freqüentes entre a favela e a violência e pela crescente legitimidade do discurso público da desordem urbana como razão dos males da cidade? Há algo fora da ordem? Serão os pobres favelados ou os discursos sobre eles?

\section{NOTAS}

E-mail dos autores: cesar@ippur.ufrj.br e luciana@ippur.ufrj.br

Este trabalho foi desenvolvido no âmbito das pesquisas "Metrópole, Desigualdades Socioespaciais e Governança Urbana" (Pronex-CNPq/Finep) e "Reestruturação Econômica e Social e Governança Urbana nas Grandes Metrópoles" $(\mathrm{CNPq} / \mathrm{CNRS}-$ França) desenvolvidas no Observatório de Políticas Urbanas e Gestão Municipal - Ippur/UFRJ-Fase e contou com a colaboração dos assistentes de pesquisa Peterson Leal Pacheco, Cynthia Campos Rangel, Carlos Eduardo Sartor, Giovanna Altomare Catão e Paulo Azevedo.

1. Trecho do discurso pronunciado pelo médico, um dos elaboradores do "problema da favela", no Rotary Club.

2. Entende-se como migrante todo aquele que residia em outro município que não o do Rio Janeiro até 1991.

\section{REFERÊNCIAS BIBLIOGRÁFICAS}

BOSCHI, R. "Populações faveladas do Rio de Janeiro. Histórico de um trabalho". Dados n.4, 1970, p.170-187.

BORGADUS, E.S. Social distance. Los Angeles, Antioch Press, 1959.

BOURDIEU, P. La distinction. Critique sociale du jugement. Paris, Editions Minuit, 1979.

Razões práticas. Rio de Janeiro, Papirus, 1993.

CASTRO, M.G. O imigrante na cidade do Rio de Janeiro. Dissertação de mestrado. Rio de Janeiro, COPPE-UFRJ, 1979.

CAVALCANTI, S. "Por trás das balas". Jornal do Brasil, 4/11/1996.

LAGO, L. Desigualdades e segregação na metrópole: o Rio de Janeiro em tempo de crise. Rio de Janeiro, Revan/Observatório de Políticas Urbanas e Gestão Municipal, 2000.

PARK, R.E. "The concept of social distance as applied to the study of racial attitudes and racial relations". Journal of Applied Sociology later Sociology and Social Research, v.8, n.6, jul.-ago. 1924, p.339-344.

PERLMAN, J. O mito da marginalidade. Rio de Janeiro, Paz e Terra, 1977.

PIMENTA, M. Para a remodelação do Rio de Janeiro. Rotary Club, out. 1926.

SILVA, L.A.M. "A política na favela". Cadernos Brasileiros n.41, maio/jun. 1967.

SIMMEL, G. On individuality and social forms: Selected writings. Levine, D.N. (ed.), Chicago, University of Chicago Press, 1971.

SOROKIN, P.A. "Espaço social e posição social”. In: CARDOSO, F.H. e IANNI, O. Homem e sociedade. Leituras básicas de sociologia geral. São Paulo, Companhia Editora Nacional, 1973.

WACQUANT, L. Os condenados da cidade. Estudos da marginalidade avançada. Rio de Janeiro, Revan/Observatório de Políticas Urbana e Gestão Municipal, 2000 (no prelo).

WILSON, W.J. The truly disadvantaged. The inner city, the underclass, and public policy. Chicago, University of Chicago Press, 1987.

ZALUAR, A. e ALVITO, M. (orgs.). Um século de favela. Rio de Janeiro, Fundação Getúlio Vargas, 1998. 